\title{
QUALITY OF LIFE DETERMINANTS IN PERSONS WITH DISABILITY AFTER MUSKULOSCELETAL INJURIES
}

DOI: 10.36740/WLek202105108

\author{
Oryna D. Detsyk, Halyna Y. Yukish, Zoya 0. Tsikhon, Rostyslav Y. Kovalchuk, Ihor M. Karpinets \\ IVANO-FRANKIVSK NATIONAL MEDICAL UNIVERSITY, IVANO-FRANKIVSK, UKRAINE
}

\begin{abstract}
The aim: To study the intrinsic and extrinsic factors affecting quality of life in persons with disability after musculoskeletal injuries. Materials and methods: A medical and social research was conducted on151 individuals with re-confirmed disability after musculoskeletal injuries.

Results: It was found that a third of people with disabilities after musculoskeletal injuries $(35.8 \pm 3.9 \%)$ has low quality of life $(\mathrm{QoL})$, females more often than males ( $0 R=$ $2.73 ; 95 \%$ Cl: 1.33-5.59). The following physical determinants of low Qo L were identified: severity of disability group (2.77; $1.29-5.92)$, severity of injury (2.73; $1.11-5.63)$ related to long-term inpatient treatment $(6.36 ; 2.55-15.86)$ and need of special tools for rehabilitation $(2.42 ; 1.20-4.92)$. It was found that QoL in people with disability is decreasing with unemployment $(4.44 ; 2.13-9.23)$ and reduction in social interaction $(2.67 ; 1.33-5.39)$ when living with children $(3.04 ; 1.50-6.16)$, complicated relationship $(5.28 ; 2.54-10.97)$ and no support in family $(3.25 ; 1.62-6.50)$. This is accompanied by an increase in the need of psychotherapy $(4.07 ; 2.10-8.24)$, risky alcohol consumption $(3.29 ; 1.19-9.07)$ and taking of sedative drugs $(2.97 ; 1.35-6.50)$. It was established such medical and social determinants of low QoL as inadequate awareness of persons with disability about content of their Individual rehabilitation program $(3.85 ; 1.69-8.76)$, insufficient covering of special tools $(3.41 ; 1.67-6.96)$ and dissatisfaction of rehabilitation efficacy $(3.79 ; 1.55-9.28)$.

Conclusions: It is necessary to improve the system of rehabilitation of persons with disability after musculoskeletal injuries in view of quality of life determinants.
\end{abstract}

KEY WORDS: Quality of life, determinants, health care management

Wiad Lek. 2021;74(5):1093-1098

\section{INTRODUCTION}

Quality of life (QoL) is a complex multidimensional concept including physical health, psychological and social well-being features. It is a great public health concern that closely relates to disability whereas represents the level of fulfilling of human needs (physical, mental, spiritual, social, etc.). QoL is a subjective indicator that is difficult to optimize without predicting its intrinsic and extrinsic determinants [1].

Today, more than 1 billion people live with some form of disability [2]. Persons with disabilities, in addition to functional limitation, have more risks associated with mental health than able-bodied people have. It indicates a casual relation between disability and low QoL [3-7].

The International classification of functioning, disability and health considers disability primarily as consequence of the interaction of human health and individual characteristics with social factors [8]. The range of modifiers of QoL decreasing in disability is very wide. There are physical factors - the type and length of disability; individual biological and socio-economic characteristics - gender, education, income, employment; psychosocial interactions - stigmatization and discrimination of persons with disabilities, social isolation, relations with family and friends [6].

\section{THE AIM}

To study the intrinsic and extrinsic factors affecting quality of life in persons with disability after musculoskeletal injuries.

\section{MATERIALS AND METHODS}

A medical and social research was performed on a representative sample of 151 individuals with re-confirmed disability due to musculoskeletal injuries after at least one course of rehabilitation. The permission for the study was obtained by the Commission on Bioethics of the Ivano-Frankivsk National Medical University (protocol No 101/8 from 12.04.2018).

Data collection was conducted during 2018 on the Ivano-Frankivsk Bureau of Medical and Social Expertise (BMSE). The random sample consisted of 114 persons (75.5\%) - with group I, 34 (22.5\%) - with group II and 3 persons $(2.0 \%)$ with group III of disability, similar to such distribution in the database of the BMSE. Other characteristics of sample were: by place of residence - urban (35.1\%) and rural (64.9\%) residents; gender - male (69.3\%), female (30.5\%); age - up to 30 years (7.3\%), $30-39$ years $(31.1 \%)$, $40-49$ years $(30,5 \%)$ and $50-59$ years $(30.5 \%), 60$ years and older $(0.7 \%)$. The questionnaire contained inquiries about 
the main socio-economic, socio-psychological, behavioral, biological parameters of QoL and lifestyle. The questions of the standardized questionnaire EQ-5D (EuroQol) were included in the author's questionnaire to assess QoL. Each of its five components (Mobility, Self-care, Usual activities, Pain/Discomfort, Anxiety/Depression) was evaluated by three-point frequency scale $(0=$ no problems; $1=$ moderate problems; 2 = extreme problems). According to the results of QoL assessment, two comparison groups were formed: 54 persons (35.8\%) with low QoL (5 points or more) and 97 persons $(64.2 \%)$ - with high QoL (less than 5 points). Statistical analysis includes: calculating the rate per 100 respondents and standard error $( \pm \mathrm{m})$ for rates; testing the null hypothesis by calculating the chi-square $\left(\chi^{2}\right)$; identifying potential low QoL determinants by calculating the odds ratio (OR) and its 95\% confidence interval (95\% CI) [9].

Methods were used: epidemiological, sociological, biostatistical.

\section{RESULTS}

Low QoL was found in one third of respondents (35.8 \pm $3.9 \%)$, regardless of age and place of residence ( $p>0.05)$. Among female respondents low QoL occurred in almost half of the cases $(52.2 \pm 7.4 \%)$, which is twice as common as among males $(28.6 \pm 4.4 \%, \mathrm{p}<0.01)$. It is proved, that female in 1.3-5.6 times increases the probability of low QoL: $\mathrm{OR}=2.73$; 95\% CI: 1.33-5.59 (Fig. 1).

The comparison groups (with low and high QoL) differed significantly in the severity of disability (Fig. 2). All respondents with group I (ie those requiring third-party care) had low QoL, and the part of persons with group II disability was almost twice as high in group with low QoL (31.5\% vs $17.5 \%$ in group with high QoL). However, the part of people with the "easiest" third group of disability among people with high QoL significantly exceeds the same indicator among people with low QoL $(82.5 \%$ vs $63.0 \%$, $\mathrm{p}<0.01)$. It was determined that the severity of disability increases the chances of reducing QoL in 1.3-6.0 times $(\mathrm{OR}=2.77$; 95 CI: 1.29-5.92; $\mathrm{p}<0.01)$ (Fig. 1) (Fig 2).

It is shown that the quality of life is also affected by the localization and severity of the injury $(\mathrm{OR}=2.50$; $95 \mathrm{CI}$ : 1.11 5.63; $\mathrm{p}<0.01$; Fig. 1$)$. In both comparison groups, about $40 \%$ received injuries of the lower extremities (Fig. 3). However, among respondents with low QoL the cause of disability was a spine fracture $(30.2 \%$ vs $14.4 \%$, respectively) twice as often as among people with high QoL and three times - polytrauma ( $11.3 \%$ vs $3.1 \%)$.

The established relationship between the severity of injury and QoL may explain why among respondents with low QoL the proportion of people whose health required long-term length stay in hospital (more than 30 days a year) was significantly higher: $38.5 \%$ compared to $9.1 \%$ among respondents with high QoL, OR=6,36 (95 CI: 2,55-15,86; $\mathrm{p}<0,001$ ). (Fig 3).

It was found that there was a much higher need for special tools for rehabilitation (crutches, wheelchairs, etc.) among respondents with low QoL: $70.4 \%$ vs $49.5 \%$ among people with high QoL ( $\mathrm{OR}=2.42$; 95 CI: 1.20-4.92, p<0.01, Fig. 1). The lack of this equipment for persons with disabilities who needed them also negatively affected the QoL: OR $=3.41$; 95 CI: $1.67-6.96(\mathrm{p}<0.01)$. There were twice as many of them among respondents with low QoL as in the comparison group $(50.0 \%$ vs $22.7 \%)$, which indicates the shortcomings of IRP implementation.

One third of people with low QoL (35.2\% vs $12.4 \%)$ indicated that they were not informed about the need for post-treatment follow-up care and control of IRP by the doctor in outpatient facility. Such lack of information about the IRP content significantly increases the chances of low QoL (OR $=3.85$; 95 CI: 1.69-8.76; $\mathrm{p}<0.001$; Fig. 1$)$. Accordingly, $87.0 \%$ respondents were dissatisfied with the results of rehabilitation in group with low QoL vs 63.9\% persons with high QoL (OR = 3.79; 95 CI: 1.55-9.28; $\mathrm{p}<0.01$; Fig. 1$)$ and among female respondents more than among males: $82.6 \%$ vs $67.6 \%(\mathrm{p}<0.05)$. Anxiety and depression, which usually accompany low QoL, apparently led to the fact that the majority of people with it admitted the need of psychotherapy $-61.1 \%$ vs $27.8 \%$ of people with high QoL $(\mathrm{OR}=4.07$; 95 CI: $2.10-8.24, \mathrm{p}<0.001$, Fig. 1$)$. At the same time, women were much more likely to express this need than men were: $65.2 \%$ vs $28.6 \%$ (p <0.001).

The relationship between QoL and social factors has been established. As can be seen in Fig. 4, involuntary unemployment due to disability significantly reduces the QoL $(\mathrm{OR}=4.44 ; 95 \mathrm{CI}: 2.13-9.23 ; \mathrm{p}<0.001)$. In general, half of the respondents (51.7\%) were forced to leave any job. However, the level of this indicator among people with low QoL was $74.1 \%$ vs $39.2 \%$ among persons with high QoL. This factor was more painful for villagers $(54.1 \%$ vs $47.2 \%$ of urban residents, $\mathrm{p}<0.05)$, males $(57.1 \%$ vs $39.1 \%$ of females, $\mathrm{p}<0.05$ ) and increased with age (from $44.7-45.5 \%$ under the age of 40 vs $56.5 \%$ among those over $40, p<0.05$ ). However, respondents cited unsatisfactory health as the main reason for their unemployment (87.4\%), regardless of gender, age, place of residence and QOL ( $p>0.05)$.

Not surprisingly, $69.5 \%$ of respondents, regardless of gender, age and place of residence ( $p>0.05)$, were forced to reduce their social activity after the establishment of a disability group, including $33.8 \%$ significantly limited visiting acquaintances, friends, circles, societies, churches, etc. At the same time, the part of those who significantly lost their social activity among people with low QoL reached half of the respondents $-48.1 \%$ vs $25.8 \%$ of respondents with high QoL. (Fig 4)

Conversely, $9.3 \%$ and $39.2 \%$ of respondents, respectively, did not believe that the fact of disability had any effect on their social activity $(\mathrm{p}<0.001)$. It is proved that a significant reduction in social activity significantly impairs the QoL of persons with disabilities after musculoskeletal injuries - OR = 2.67; 95 CI: 1.33-5.39; $\mathrm{p}<0.001$ (Fig. 4).

Family support is important for social rehabilitation. The majority among the respondents were married (65.3\%). However, the rest did not have a spouse: $18.7 \%$ were never married, $14.0 \%$ were divorced and $2.0 \%$ were widowed. More than half of the respondents (57.6\%) indicated that 

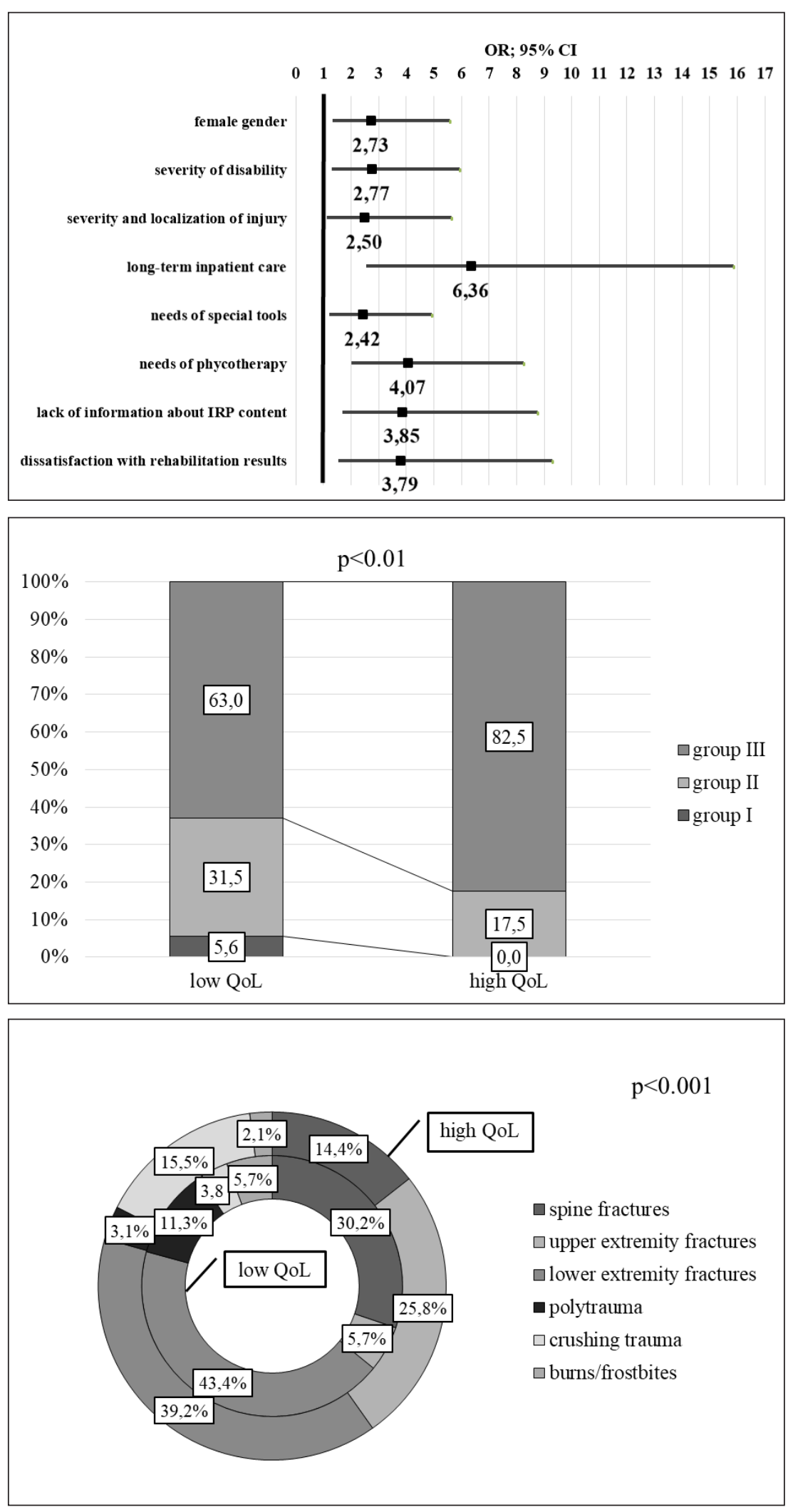

Fig. 1. Biological, medical and organizational factors influencing quality of life in persons with disability after musculoskeletal injury

Fig. 2. Distribution by disability groups in respondents with low and high quality of life

Fig. 3. Structure of disability causes in respondents with low and high quality of life they live with a husband or wife, another third (33.8\%) - with children, one in four $(23.8 \%)$ with parents, and $13.2 \%$ without anyone. At the same time, it was found that only living with children has a significant negative impact on QoL in disability after musculoskeletal injuries (OR $=3.04$; 95 CI: 1.50-6.16; p<0.001; Fig. 4 ). On the other hand, almost half of the respondents $(47.0 \pm 4.1 \%)$ complained about the deterioration of relations between family members after the establishment of a disability group, including $11.9 \%$ - about their significant complication until the breakdown of the relationship. Such complaints were especially typical for the surveyed women $-67.4 \%$, 


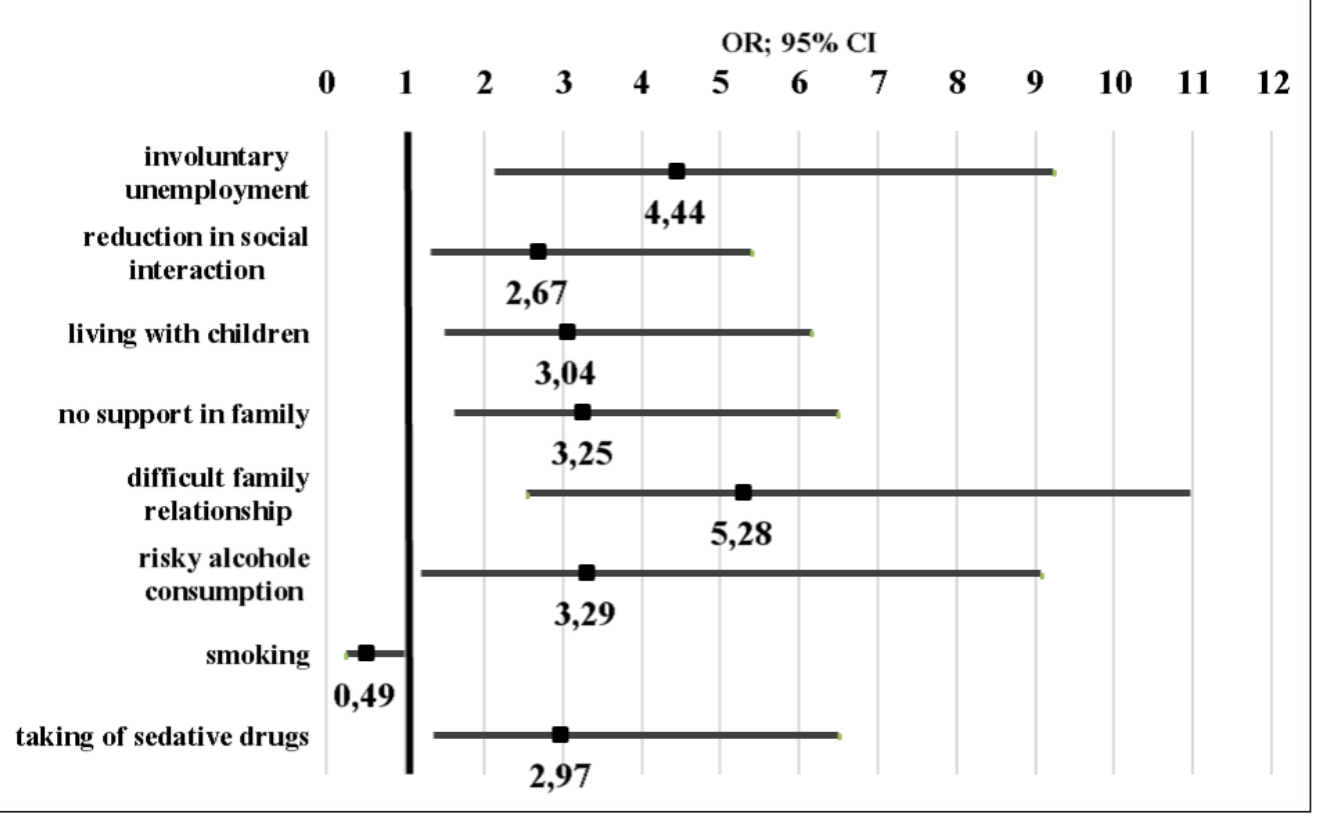

Fig. 4. Social and behavioral factors influencing quality of life in persons with disability after musculoskeletal injury
$19.6 \%$ of which were assessed as catastrophic deterioration, vs $38.1 \%$ and $8.6 \%$ among male respondents, respectively $(\mathrm{p}<0.01)$. Such complaints was significantly more common in low QoL than in high $-72.2 \%$ and $25.9 \%$ vs $33.0 \%$ and $4.1 \%(\mathrm{p}<0.001)$. It is proved that any deterioration of family relations increases the chances of low QoL in 2.5-11.0 times $(\mathrm{OR}=5.28$; 95\% CI: 2.54-10.97; $\mathrm{p}<0.001$; Fig. 4). Almost $40 \%$ of respondents $(41.1 \pm 4.0 \%)$ indicated that they do not feel adequate support from family and relatives, again more emphasized among women than among men $(69.6 \%$ vs. $28.6 \%, \mathrm{p}<0.001)$, and with low QoL (59.3\% vs $30.9 \%$ with high QoL, $\mathrm{p}<0.01)$. The lack of support from relatives 1.6-6.5 times increases the chances of reducing QoL $(\mathrm{OR}=3.25$; 95\% CI: 1.62-6.50; $<<0.01$, Fig. 4).

It was detected that low QoL is usually accompanied by risky alcohol consumption (OR $=3.29$; 95\% CI: 1.19 9.07; $\mathrm{p}<0.01$, Fig. 4). One in five respondents with low QoL (20.4\% vs. 7.2\% in the comparison group) stated that they use it 2-4 times a month. Moreover, this is all - males ( $17.1 \%$ vs $0 \%$ among women, $\mathrm{p}<0.01)$.

Instead, the presence of another bad habit - smoking, was slightly lower among people with low QoL than with high QoL - 31.5\% vs 48.5\%, p> 0.05, OR=0.49; 95\% CI: 0.24-0.98 (Fig. 4). Smoking is also more common among men $-53.3 \%$ vs $17.4 \%$ of women $(p<0.001)$.

It was found that low QoL is accompanied by twice the frequency of sedative drugs $-35.2 \%$ of people with low vs $15.6 \%$ of people with high QoL $(\mathrm{OR}=2.97$; $95 \% \mathrm{CI}: 1.35-$ $6.50 ; \mathrm{p}<0.05$, Fig. 4) and is more characteristic of urban residents than rural $(28.3 \%$ vs $19.3 \%$, p <0.05).

\section{DISCUSSION}

The study, as others similar $[1,10,11]$, confirmed that disability after musculoskeletal injuries in a third of cases is accompanied by low QoL, and in women twice as often as in men [5, 12]. However, Noh J.-W. et al. [5] explain such gender differences reduced access to material and social conditions, low socioeconomic status of female vs male. Instead, the results of our study indicate the priority influence of socio-psychological factors. For example, women were much more likely to complain of a lack of family support and deteriorating family relationships after becoming disabled, as well as the need for psychotherapy. These factors are important determinants of low QoL according to this study.

Our study also found that QoL decreases with increasing severity of injury and disability. Similar results are shown in the research of Brasel K.J. et al. [10]. It is logical that the severity of the injury directly correlates with the length stay in hospital. Our data, as well as the results of the study van Delft-Schreurs C.C.H.M. et al. [11], prove that the length stay in hospital is also one of the determinants that reduce QoL. In addition, the need for special tools may be the same determinants of QoL, covariant with the severity of disability, as we have shown.

These studies once again confirmed the importance of social factors for QoL of people with disabilities, especially after musculoskeletal injuries, in particular, involuntary unemployment, reduction in social activity and social communications against the background of no family support (loss of the so-called "buffer hypothesis" of social support [6]). Similar results were obtained by van Delft-Schreurs C.C.H.M. et al. [11], demonstrating that patients who returned to work or lived with others had significantly higher QoL rates than the unemployed and single. In addition, our study found a significant effect of family composition on QoL. It was found that living with children increases the chances of decreasing QoL, apparently due to a sense of responsibility, awareness of their own weakness and unwillingness to be a burden to them. 
We have found contradictory results regarding the relationship between QoL and behavioral factors such as alcohol use and smoking. The study showed that frequent (2-4 times a month) alcohol consumption is a modifier of low QoL, especially in males. This may be explained by the results of the study Mathiesen E.F. et al. [13], who proved that excessive alcohol consumption increases psychological distress, worsens social interactions and QoL in general. However, our study found that among respondents with high QoL there were more smokers than in the group with low QoL, despite the fact that scientific sources, in particular Goldenberg M. et al. [14], prove that there is a negative relationship between smoking and quality of life. Perhaps the reason is that we have studied QoL among people with disabilities, and perhaps malaise is an additional factor that motivates them to get rid of this bad habit, especially in those who smoke irregularly. In any case, these aspects of QOL require more detailed studying.

The rehabilitation system for people with disabilities after musculoskeletal injuries also requires further study and development of improving measures. After all, the study shows that despite the fact that respondents took at least one course of rehabilitation, a significant part of them were insufficiently covered with special tools for rehabilitation, inadequately informed about the content of their IRP and dissatisfied with the efficacy, which significantly reduced the QoL of respondents.

\section{CONCLUSIONS}

It was found that a third of people with disabilities after musculoskeletal injuries (35.8 $\pm 3.9 \%)$ has low quality of life, females more often than males $(\mathrm{OR}=2.73$; 95\% CI: 1.33-5.59).

The following physical determinants of low quality of life were identified: severity of disability group $(2.77$; $1.29-5.92)$, severity of injury $(2.73 ; 1.11-5.63)$ related to long-term inpatient treatment $(6.36 ; 2.55-15.86)$ and need of special tools for rehabilitation $(2.42 ; 1.20-4.92)$.

It was found that quality of life in people with disability is decreasing with unemployment $(4.44 ; 2.13-9.23)$ and reduction in social interaction $(2.67 ; 1.33-5.39)$ when living with children $(3.04 ; 1.50-6.16)$, complicated relationship (5.28; $2.54-10.97)$ and no support in family $(3.25$; 1.62 6.50). This is accompanied by an increase in the need of psychotherapy (4.07; 2.10-8.24), risky alcohol consumption $(3.29 ; 1.19-9.07)$ and taking of sedative drugs (2.97; $1.35-6.50)$.

It was established such medical and social determinants of low quality of life as inadequate awareness of persons with disability about content of their Individual rehabilitation program $(3.85 ; 1.69-8.76)$, insufficient covering of special tools $(3.41 ; 1.67-6.96)$ and dissatisfaction of rehabilitation efficacy $(3.79 ; 1.55-9.28)$.

Further research will be the development of measures to improve the rehabilitation system for people with disability after musculoskeletal injuries in view of quality of life determinants.

\section{REFERENCES}

1. Rajati F., Ashtarian H., Salari N. et al. Quality of life predictors in physically disabled people. J Educ Health Promot. 2018;7:61. doi:10.4103/jehp. jehp_115_17

2. World Health Organization and World Bank Group. World report on disability. WHO, Geneva. 2011.

3. Milner A., Kavanagh A., McAllister A. et al. The impact of the disability support pension on mental health: evidence from 14 years of an Australian cohort. Aust N Z J Public Health. 2020;44(4):307-12. doi:10.1111/1753-6405.1301.

4. Aitken Z., Simpson J.A., Bentley R. et al. Does the effect of disability acquisition on mental health differ by employment characteristics? A longitudinal fixed-effects analysis. Soc Psychiatry Psychiatr Epidemiol 2020;55:1031-9. doi:10.1007/s00127-019-01783-x.

5. Noh J.-W., Kwon Y.D., Park J. et al. Relationship between Physical Disability and Depression by Gender: A Panel Regression Model. Plos One. 2016;11(11):e0166238. doi:10.1371/journal.pone.0166238.

6. Tough H., Siegrist J., Fekete C. Social relationships, mental health and wellbeing in physical disability: a systematic review. BMC Public Health. 2017;17:414. doi:10.1186/s12889-017-4308-6.

7. Kagan M., Itzick M., Tal-Katz P. Demographic, psychosocial, and health- and disability-related factors associated with psychological distress among people with physical disabilities. Rehabil Psychol. 2018;63(3):392-399. doi:10.1037/rep0000206.

8. World Health Organization. The international classification of functioning, disability and health. WHO, Geneva. 2001.

9. Forthofer R.N., Lee E.S., Hernandez M. Biostatistics: A Guide to Design, Analysis, and Discovery. Amsterdam: Elsevier Academic Press. 2007; 502.

10. Brasel K.J., DeRoon-Cassini T., Bradley C.T. Injury Severity and Quality of Life: Whose Perspective Is Important? J Trauma Inj Infect Crit Care. 2010;68(2):263-68. doi:10.1097/TA.0b013e3181caa58f.

11. Van Delft-Schreurs C.C.H.M., Van Bergen J.J.M., De Jongh M.A.C. et al. Quality of life in severely injured patients depends on psychosocial factors rather than on severity or type of injury. Injury. 2014;45(1):32026. doi:10.1016/j.injury.2013.02.025.

12. Holbrook T.L., Hoyt D.B. The Impact of Major Trauma: Quality-of-Life Outcomes AreWorse in Women than in Men, Independent of Mechanism and Injury Severity. J Trauma Inj Infect Crit Care. 2004;56(2):284-290. doi:10.1097/01.TA.0000109758.75406.F8.

13. Mathiesen E.F., Nome S., Eisemann M. et al. Drinking patterns, psychological distress and quality of life in a Norwegian general population-based sample. Qual Life Res. 2012;21:1527-36. doi:10.1007/ s11136-011-0080-8.

14. Goldenberg M., Danovitch I., IsHakW.W. Quality of life and smoking. Am J Addict. 2014;23(6):540-562. doi:10.1111/j.1521-0391.2014.12148.x

Article is conducted within complex scientific research "Discussion of strategies and technologies improve health and the needs of the population in high-quality medical care" (deadlines 2017-2021, State registration number 0117U001669) in Ivano-Frankivsk National Medical University.

\section{ORCID and contributionship:}

Oryna Z. Detsyk: 0000-0003-3979-9455 A, C, D, E, F

Halyna Y. Yukish: 0000-0001-5268-596 ${ }^{A, B, D, E}$

Zoya O. Tsikhon: 0000-0002-7231-1225 A, B, E

Rostyslav Y. Kovalchuk: 0000-0001-9862-9312 ${ }^{A, B, E}$

Ihor M. Karpinets: 0000-0002-5030-1667 ${ }^{A, B, E}$ 


\section{Conflict of interest:}

The Authors declare no conflict of interest.

\section{CORRESPONDING AUTHOR}

Oryna D. Detsyk

Ivano-Frankivsk national medical university

2 Halytska Street, 76000 Ivano-Frankivsk, Ukraine

tel: +380503733309

e-mail: odetsyk@ifnmu.edu.ua

Received: 27.12 .2020

Accepted: 30.03 .2021

A - Work concept and design, B - Data collection and analysis, C - Responsibility for statistical analysis,

D-Writing the article, $\mathbf{E}$-Critical review, $\mathbf{F}$ - Final approval of the article 